JD. Methods and basic data of case-control study of leukaemia and Ismphoma among ioung people near Sellaficld nuclear plant in West Cumbria. Br Med $f$ 1990;300:429-3t. 17 Februar:

3 Black 1). Investhgation of the possible incriased incidence of cancer in West Cumbria. London: HMSO, 198

4 Gardner MJ, Hall AJ, Downes S, Terrell JD. Follow up studs of hildren born to mothers resident in Seascale, West Cumbria children born to mothers resident in Seasc

5 Kinlen LJ. Evidence for an infective cause of childherd leukacmia: comparison of a Scotish new town with nuclear reprocessing sites in Britain. Lancet 1988;ii:1323-7.

6 Kinlen LJ. The relevance of population mixing to the actiology of childhood leukaemia. In: Crosbie WA, Gitus JH, eds. Medical response to effects of ionising radiation. London: Elsevicr 1989:272-8

SIR, -- The article by Professor Martin J Gardner and colleagues evokes very difficult problems of inference. If we take the most worrying of over 80 comparisons, that in which four fathers of 46 children with leukaemia had been exposed to more than $100 \mathrm{mSv}$ before conception against three fathers of the far more numerous controls, the usua relative risk would be $(4 \times 273) /(3 \times 42)=8.67$; the authors, who do not describe their procedure beyond mentioning a computer program available from Seattle, give $8 \cdot 38$, which is effectively the same. Four cases were observed when about 0.5 would be expected.

With such small numbers so pronounced a disparity after selecting the most extreme difference from so many choices would not be unduly unlikely. Even if causally connected with radiation such selection would tend to exaggerate any estimate of relative risk even if the association were real, and the much quoted eightfold risk needs to be interpreted as both very imprecise and biased. The authors, who do not allow for bias, quote a range of $1 \cdot 35-51 \cdot 99$.

Though infection as a cause of the undoubted clustering remains a plausible hypothesis, stan dard statistical methods are inappropriate to tes this as one person would cause another to be predisposed to some disorder in himself or in those he is liable to infect so that one event could lead to more than one consequence. If radiation were causal confidence ranges would be appropriate, but this is a circular argument.

As yet the claim of a substantial effect related to external exposure to radiation and mediated genetically would seem inadequately buttressed against the substantial negative evidence from Hiroshima and Nagasaki; the absence of any simple mechanism restricted to the male gametes and not manifest in the non-leukaemic cells of most children with leukaemia; the rarity of familial cases related to background radiation; and the lack of evidence of any such effect from medical exposure in either patients or radiologists.

Whatever the cause of this apparent association there are strong reasons for the preferential employment in high radiation areas of those whose expectation of offspring, based on age and sex, is low. The continuing failure of the nuclear industry to exploit such simple opportunities for reducing the genetic risk, which is the product of the dose received by children subsequently conceived, remains unexplained.

J H EDWARDS

Genetics Laboratory,

Oxford OX1 30U

1 Gardner MJ, Snce MP, Hall AJ, Powell CA, Daunes S, Terrell JI). Results of case-control study of leukaemia and lymphoma among young people near Sellafield nuclear plant in West Cumbria. Br Med f 1990;300:423-9. 17 February.

AUTHORS' REPLY, .... In reply to Dr Leo Kinlen's letter we would like to make the following comments.

The examination of occupational radiation exposure of parents before their child's conception was one of the original main hypotheses of our study and in fact was discussed and documented as such by the Black inquiry team.' From this stance one of the measures of radiation dose it seemed appropriate to consider was the total dose accumulated before conception. Although cumulative radiation dose is likely to correlate with preconceptual length of residence in Seascale, it would be appropriate to match on length of residence only if it were independently suspected of determining the risk of leukaemia. There is no published evidence of such an effect. In fact, Dr Kinlen has postulated that recent incomers to Seascale as well as the local population may be among those susceptible to any effects of population mixing on the incidence of childhood leukaemia. ${ }^{2}$

The proportion of cases of leukaemia and nonHodgkin's lymphoma excluded from the radiation analysis because of lack of adequate tracing of the father's details for linkage to the Sellafield workforce file was eight out of $74(11 \%)$; for area controls it was 48 out of $499(10 \%)$, and for local controls it was 51 out of $487(10 \%)$. The percentages are very similar. The reason why the loss of controls seems greater than that of cases in table VI of our results-- 95 out of 499 area controls (19\%) and 98 out of 487 local controls $(20 \%)$--is that not only were the 48 and 51 controls mentioned earlier omitted but also 47 area and 47 local controls (whose fathers were fully identified) that were matched to the eight excluded cases. We did not in fact use the questionnaire to ask dates of birth but obtained these through both medical records in Cumbria and the NHS central register. Thus the proposed bias did not operate.

Dr Kinlen points to three cases omitted because, although diagnosed in Seascale, they were not born in West Cumbria. Along with other similar cases, which we mentioned, in patients who were diagnosed but not born in West Cumbria they will be reported subsequently. It should be noted, however, that we have found that the excess of leukaemia in Seascale has been concentrated among children born in the village and not among those moving in afterwards and attending local schools. ${ }^{4}$ This was partly our rationale, although not stated in the papers, for initially analysing cases in patients both born and diagnosed in West Cumbria. The case in a patient from Seascale who was identified after leaving West Cumbria does not belong to this case-control study but is included in the extension of our Seascale birth cohort, which we are now linking to the Sellafield workforce file to examine radiation dosimetry.

It is strange that Professor Edwards says that we did not describe our procedure apart from a computer program as we stated the method to be conditional logistic regression analysis within matched sets of cases and controls and gave a reference to a standard textbook. We agree that several preformulated hypotheses were tested, but all of the "over 80 comparisons" that he suggests we made were not independent of each other and those in table VI of our paper show some consistency. The numbers of cases are, nevertheless, admittedly small and further work is necessary. There is not, however, "substantial negative evidence" from Japan on this point as the numbers from the study mentioned were equally small, with only five observed compared with $5 \cdot 2$ expected cases of leukaemia among children of irradiated men. ${ }^{5}$ Our paper concentrated on men because women essentially did not work at Sellafield in the radiation areas, but we did give some information on mothers in the text.

MARTIN J GARDNER

MRC Environmental Epidemiology Unit,

Southampton Gencral Hospital,

Southampton S() 9 XY MICHAEL P SNEE 1 Black D. Incestigation of the possible increased incidence of cancer
in W'ist Cumbria. Lendon: HMSO, 1984 .
2 Kinlen L. The relcvance of population mixing to the actiology of
childhood leukacmia. In: Crosbic WA. Gittus JH. eds. Medical
respomse to effects of ionising rudiation. London: Elserier, 1989: 2728
Gardner MJ, Hall AJ, Downes S, Terrell J1). Follow up study of children born to mothers resident in Seascale, West Cumbri birth cohort. Br Med f 1987;295:822-7.

4 Gardner MJ, Hall AJ, Downes S, Terrell JD. Follow up study of children born elsewhere but attending schools in Seascale, West Cumbria (schools cohort). Br Med f 1987; 295:819-22.

Ishimaru T Ichimaru M, Mikami M. Leukaemie incidence umong individuals sxposed in ucero, children of atomic bomb sumvivors and their controls, Hiroshima and Nagasaki, 1945-79. Hiroshima: Radiation Fffects Rerand Nagasaki, 1945-79. Hiroshima: nical Report 11-81.)

\section{Infectious complications of blood transfusion}

SIR, - In the recent series on blood transfusion Drs John A J Barbara and Marcela Contreras mention the possibility of contamination of donated blood with Yersinia species.' We wish to illustrate the diagnostic difficulties that this may pose by reporting a fatal case of Yersinia enterocolitica septicaemia associated with blood transfusion in which the initial diagnosis was one of incompatible blood transfusion.

A 75 year old man became febrile and shocked when a transfusion of 25 day old whole blood was started after an elective hip replacement for osteoarthritis. Despite treatment with gentamicin and cefotaxime he developed disseminated intravascular coagulopathy and died within 12 hours of transfusion. At necropsy he was found to have had a coronary thrombosis and no ileitis or abdominal lymphadenopathy was found. Venous blood culture grew $Y$ enterocolitica biotype 2 serotype 09 after six days' incubation. The remainder of the transfused unit was used for haematological incompatibility testing, and by the time the recipient's cultures were positive the blood was not available for culture.

Since the first report from South Africa in $1982^{2}$ 14 acute transfusion reactions associated with $Y$ enterocolitica, with nine causing death, have been described outside the United Kingdom, as summarised in two recent reviews. ${ }^{+}$A non-fatal transfusion reaction in which $Y$ enterocolitica was isolated from the transfused unit but not from the recipient has been reported from Scotland. Serological evidence of donor infection was found in 10 out of 12 donors traced, but only four were symptomatic. In all but one case the unit of blood was over three weeks old at the time of transfusion.

It is important to note that unlike other contaminating organisms $Y$ enterocolitica does not cause visible haemolysis of stored blood.' Given that the signs and symptoms of transfusion of incompatible blood ${ }^{6}$ may resemble reactions to contaminated blood an immediate clinical diagnosis of this rare complication of blood transfusion is unlikely. We emphasise that standard microbiological investigation' with culture of donor blood at $20^{\circ} \mathrm{C}$ and $37^{\circ} \mathrm{C}$ is indicated after any severe transfusion reaction with no obvious serological cause. After transfusion is stopped treatment with a range of antibiotics likely to act against most Gram negative contamination organisms should be considered (for example, ciprofloxacin or ceftazidime)

The future development of endotoxin assays, anti-endotoxin immunotherapy, and wider use of plasmapheresis may offer the best hope of reducing mortality from this unusual variety of endotoxic shock. Haematologists and medical microbiologists should report suspected cases to the Public Health Laboratory Service Communicable Diseases Surveillance Centre.

MICHAEL PRENTICE DELIA COPE

Public Health Laboratory and

Department of Microbiology,

Leicester Roval Infirmary, Leicester LEı SWW

MICHAEL WEINBREN JEAN O'DRISCOLL

Department of Microbiology,

Queen Mary's Hospital, London SW15 
I Barbara JAJ, Contreras $M$. Infectious complications of blood transfusion: bacteria and parasites. $\mathrm{Br} M \mathrm{Med} / \mathrm{J}$ 1990;300:386-9. 2 Stenhouse MAE, Milner LV. Yersinia enterocolitica; a hazard in blood transfusion. Transfusion 1982;22:396-8.

Centers for Disease Control. Yersinia enterocolitica bacteremia and endotoxin shock associated with red blood cell transfusion - United States, 1987-1988. MMWR 1988;37:577-8.

+ Jacobs J, Jamaer D, Vandeven J, Wouters M, Vermylen C, Vandepitte J. Yersinia enterocolitica in donor blood: a case report and review. F Clin Microbiol 1989;27:1119-21.

5 Mitchell R, Barr A. Transfusion reaction due to Yersinia enterocolitica. Communicable Diseases (Scotland) Weekly Report $1988: 50: 4$.

6 Contreras M, Mollison PL. Immunological complications of transfusion. Br.Med f 1990;300:173-6

Barbara JAJ. Aicrobiology in blood transfusion. Bristol: Wright, 1983:90-6.

\section{HTLV-I infection in British and Jamaican relatives of British patients with tropical spastic paraparesis}

SIR, - The results of the study by Dr J K Cruickshank and colleagues on the seroprevalence of human $\mathrm{T}$ cell leukaemia lymphoma virus type I (HTLV-I) in the families of 11 Jamaican immigrants with tropical spastic paraparesis in London' differ from our results in the west midlands. ${ }^{2}$ In our study most, though not all, of the available United Kingdom resident members of the families of seven patients with tropical spastic paraparesis agreed to testing for HTLV-I antibodies. All of the patients were women-six from Jamaica and one from Saint Vincent. Their HTLV-I state was established by using passive particle agglutination, enzyme linked immunosorbent assay (ELISA), and immunofluorescence tests. ${ }^{2}$ All three husbands tested positive; one of them had adult $T$ cell leukaemia lymhoma. Of five Jamaican born children, one tested positive.

Whereas Dr Cruickshank and colleagues did not find any of 14 children born in the United Kingdom to be seropositive, two out of 10 children born in the United Kingdom whom we tested were seropositive. They were both the daughters of a woman with tropical spastic paraparesis (onset 1980 ) and a man with adult $T$ cell leukaemia lymphoma (onset 1986). One was aged 28 and had visited Jamaica for a few months when aged 13 and 25; the other was aged 21 and had never visited the West Indies. They had two seronegative younger brothers who were born in the United Kingdom and were living in the west midlands and one seropositive older sister who was born in Jamaica. Two other brothers and two other sisters who were born and resident in Jamaica were not tested. All of the children in our family study (except one seronegative son) were breast fed, and none of the seropositive relatives had received a blood transfusion.

The fact that the two daughters who were born in the United Kingdom were positive for HTLV-I antibody indicates that childwen of Jamaican immigrants with tropical spasuic paraparesis may seroconvert in this country, not just in the West Indies. When the data for United Kingdom resident children of patients with tropical spastic paraparesis in the west mildlands and London are combined five out of $14(36 \%)$ Jamaican born children and two out of $24(8 \%)$ United Kingdom born children were seropositive; this difference is not significant (Fisher's exact test). Although maternal transmission may not be the only route of infection in these children, these results do not support the arguments of Dr Cruickshank and colleagues against maternal transmission as the main route. The numbers in both the London and west midlands studies are small, but further testing of the available families of patients with tropical spastic paraparesis or adult $T$ cell leukaemia lymphoma may provide an explanation for familial clustering of HTLV-I infection.

Dr Cruickshank and colleagues state that there are no available and adequate data on HTLV-I seroprevalence in Jamaican born immigrants in Britain except their own (unpublished) study of 81 Afro-Caribbean subjects in London, in whom they found an HTLV-I seroprevalence of $2 \cdot 5 \%$. We have carried out anonymous testing for HTLV-I antibody in Afro-Caribbeans in the west midlands and found that seven out of $192(4 \%)$ of West Indian born subjects were seropositive, but none of 403 United Kingdom born subjects of AfroCarribean origin were seropositive. Despite different study methods the seroprevalences in the west midlands and London groups of West Indian immigrants were not significantly different (Fisher's exact test) and are comparable with the seroprevalences reported in Jamaica. ${ }^{3}$ The difference in seroprevalence between the United Kingdom born and immigrant Afro-Caribbeans in our study is significant $\left(\chi^{2}\right.$ test, $\left.p<0.001\right)$, but this difference has not been found in the family studies.

Queen Elizabeth Hospital

SIMON NIGHTINGALE

Birmingham B15 2TH

East Birmingham Hospital

Birmingham

1 Cruickshank JK, Richardson JH, Morgan OStC at al Screening for prolonged incubation of HTLV-I infection in British and Jamaican relatives of British patients with tropical
spastic paraparesis. Br Med $\mathcal{F}$ 1990;300:300-4. (3 February.) Mowbray J, Mawson S, Chawira A, et al. Epidemiology of human T-cell leukaemia/lymphoma virus type 1 (HTLV-1) infections in a subpopulation of Afro-Caribbean origin in England. $7 \mathrm{Med}$ Virol 1989;29:289-95.

3 Murphy EL, Hanchard B, Figueroa JP, et al. Modelling the risk of adult $\mathrm{T}$-cell leukaemia/lymphoma in persons infected with HTLV-1. Int f Cancer 1989:43:250-3.

\section{Housing and health}

SIR, - I would like to congratulate Stella Lowry on her thoughtful articles on housing and health.' May I put in a plea, however, for doctors to keep a foot in both camps - in the real if chaotic role of helping to prioritise housing applicants and as white knights crusading for decent housing.

I agree that in most cases a doctor's opinion is superfluous, and as stated in the article a medical degree is not required to spot the most needy cases. It can be helpful, however, in deciding whether a disability is permanent and stable, curable over time, or progressive.

Another reason for pleading for the continued involvement of a doctor is that over the years requests for rehousing have provided a fruitful source of case finding for young and elderly handicapped people, who have either not contacted or not been helped by the statutory services. These include those with deteriorating multiple sclerosis, people with multiple diseases living in substandard housing, travellers with handicapped children, and so on

Incidentally, the new district public health annual reports are a heaven sent platform for campaigning for decent, affordable housing and for illustrating the deteriorating position vis à vis its provision.

LINDSAY ELLIOTT

Medway Health duthority

(iillingham,

Kent $M 175$ N

1 Lowry S. Housing and health housing for people with special needs. Br Aled f 1990; 300:321-3. (3 February.

\section{Cancer of the oesophagus}

SIR,-Dr I C M Paterson' accuses $\mathrm{Mr}$ John Bancewicz $^{2}$ of being unbalanced in his article on cancer of the oesophagus and then proceeds himself to offer a most unbalanced view on the subject. The gist of his letter is that surgery has no advantage over radiotherapy, and he quotes the reviews by Earlam and Cunha-Melo. ${ }^{3}$ In fact one of these critical reviews of surgery" reported a $12 \%$ and not a $4 \%$ survival at five years. In patients leaving hospital the five year survival went up to $18 \%$. On the other hand the review of radiotherapy showed a five year survival of $6 \% .^{+}$These figures are in line with those in most published work. Maybe this would explain why Earlam's prospective trial between surgery and radiotherapys failed because of inadequate recruitment, as Dr B S Mantell complained in his letter.

Of course surgery can be offered only to a selected group of patients, and this has been fully recognised by us. Surgery, however, gives such patients the best chance of prolonged survival. If surgery is done in a specialised unit with a low mortality and short stay in hospital then Dr Paterson need not worry too much about its cost effectiveness. Radiotherapy may be cheaper, but the patient's interest is paramount.

F D SALAMA

City Hospital,

Nottingham, NG5 IPB

I Paterson ICM. Cancer of the oesophagus. Br Med $\mathcal{J} 1990 ; 300$ 261. (27 January.)

Bancewicz J. Cancer of the oesophagus. Br Med f 1990;300:3. (6 January.)

Earlam R, Cunha-Melo JR. Oesophageal squamous carcinoma I A critical review of surgery. Br f Surg 1980;67:381-90.

Earlam R, Cunha-Melo JR. Oesophageal squamous carcinom II. A critical review of radiotherapy. Br $\mathcal{F}$ Surg 1980;67:457-61. 5 Earlam RJ. An MRC prospective randomised trial of radiotherapy versus surgery for operable squamous cell carcinoma of the ocsophagus. AnnR Coll Surg Engl (in press).

6 Mantell BS. Cancer of the oesophagus. Br Med f 1990;300:261 (27 January.)

Salama FD, Leong YP. Resection for carcinoma of the oesophagus. 7 R Coll Surg Edinb 1989;34:97-100.

\section{Stone fish bite}

SIR,-O Other readers have drawn your attention to the fact that the injury produced by a stone fish is caused by the highly venomous spines ${ }^{12}$ and not a bite as suggested.

The stone fish is extremely hard to see in the natural environment, and practically all stings reported occur on the feet or hands. In an isolated area the extreme pain and distress plus impending local tissue damage can be difficult to manage, especially in the absence of antivenom. The only stone fish antivenom available is produced by our laboratories. We receive many reports of its use and have no reason to doubt its effectiveness when given promptly with other recommended management. ${ }^{+}$

Advice on first aid and treatment has been under constant scrutiny for some years. We believe that the current protocols are rational and minimise injury to the patient. These protocols are modified depending on the type of venomous organism concerned. With a stone fish sting we agree that appreciable pain relief is often obtained by bathing the injured part in warm but not scalding water. Sometimes cooling water for boat engines has been used for this purpose. There is no evidence that hot water denatures the venom: indeed, the pain often returns instantly when the heat treatment is stopped. Local anaesthetics may give some relief, but in a severe case a regional nerve block may be indicated, as are systemic opiates. Antivenom rapidly reduces symptoms, especially when given early.

The use of a tourniquet after a stone fish sting will do nothing but increase the patient's discomfort and enhance the local necrotising effects of the venom. In Australia arterial tourniquets are not recommended in the management of any type of envenomation. In most cases, such as those of snake bites, the pressure immobilisation technique is used, which has been shown successfully to retard the movement of venom from the bitten or 